\title{
Implications of the law on video recording in clinical practice
}

\author{
Kirsten R. Henken • Frank Willem Jansen • \\ Jan Klein · Laurents P. S. Stassen • \\ Jenny Dankelman · John J. van den Dobbelsteen
}

Received: 5 October 2011/Accepted: 26 March 2012/Published online: 27 April 2012

(c) The Author(s) 2012. This article is published with open access at Springerlink.com

\begin{abstract}
Background Technological developments allow for a variety of applications of video recording in health care, including endoscopic procedures. Although the value of video registration is recognized, medicolegal concerns regarding the privacy of patients and professionals are growing. A clear understanding of the legal framework is lacking. Therefore, this research aims to provide insight into the juridical position of patients and professionals regarding video recording in health care practice.

Methods Jurisprudence was searched to exemplify legislation on video recording in health care. In addition, legislation was translated for different applications of video in health care found in the literature.

Results Three principles in Western law are relevant for video recording in health care practice: (1) regulations on privacy regarding personal data, which apply to the gathering and processing of video data in health care settings; (2) the patient record, in which video data can be stored; and (3)
\end{abstract}

K. R. Henken $(\bowtie) \cdot$ F. W. Jansen · J. Dankelman .

J. J. van den Dobbelsteen

Department of Biomechanical Engineering, Delft University of

Technology, Mekelweg 2, 2628, CD, Delft, The Netherlands

e-mail: K.R.Henken@tudelft.nl

F. W. Jansen

Department of Gynecology, Leiden University Medical Centre, Leiden, The Netherlands

J. Klein

Institute of Health Policy and Management, Erasmus University

Rotterdam, Rotterdam, The Netherlands

L. P. S. Stassen

Department of Surgery, University Hospital Maastricht,

Maastricht, The Netherlands professional secrecy, which protects the privacy of patients including video data. Practical implementation of these principles in video recording in health care does not exist.

Conclusion Practical regulations on video recording in health care for different specifically defined purposes are needed. Innovations in video capture technology that enable video data to be made anonymous automatically can contribute to protection for the privacy of all the people involved.

Keywords Health care - Law $\cdot$ Patient safety - Privacy · Surgery · Video

Video imaging is becoming increasingly important in health care, especially in endoscopic surgery. Although the advantages of video recording are recognized, concerns regarding the privacy of patients and professionals related to video recording are growing. Yet the legal framework of video recording in clinical practice has never been described clearly before.

The advantages of recording images in a medical setting are numerous [1-3], and consequently a wide variety of applications in health care has been suggested. In endoscopic surgery, videos are obviously indispensible. Endoscopic videos are primarily used in real time during minimally invasive surgery (MIS), but the video images also may be stored for later use in education or evaluation.

Regular video cameras are present throughout health care as well. Video recording allows reviewing of results at any time from any location. Video data are most commonly used as a research tool to assess the skills of professionals and students or to monitor processes for the purpose of improving quality, efficiency and safety of care.

Another application of video data is in the education of students and professionals. The latest development in video 
monitoring is active control and improvement in quality of care with systems that provide direct feedback to the health care providers by real-time analysis of recorded processes. An example of such a system is described by Guerlain et al. [4]. This digital system, it is suggested, can archive and analyze the complete operative environment, allowing prospective studies of operative performance, intraoperative errors, team performance, and communication. Before such a system can be implemented, it must be validated thoroughly, and performance metrics have to be identified.

Although video recording can be a powerful tool for various purposes, concerns have hampered implementation of systematic video recording. One concern is that videos invade the privacy of patients and professionals. In addition, professionals may fear that video data might be used for punitive or controlling purposes, as in the society described by George Orwell in his novel Nineteen Eighty-Four.

These concerns, however, are mostly due to unfamiliarity with the legal framework on video recording in health care. Addressing the question of the extent to which the law comes into play is becoming more urgent because pressure from society to implement systematic video recording is increasing. In the Netherlands, the Inspectorate of Health Care stated in a report on MIS [5] that examination of the competency of laparoscopists based on national criteria is needed, as well as periodical assessment by colleagues via video recording of laparoscopic interventions. The Dutch Society of Endoscopic Surgery in the Netherlands currently is defining guidelines with respect to video recordings and is therefore at the forefront. However, developments such as these are seen worldwide. An extensive review that pertains to Dutch law on video in health care can be found in Blaauw and Hubben [6].

The current report aims to provide insight into the legal implementation framework of video recording in health care in Western countries. It focuses on the privacy and the juridical position of the patient and the professional. This report discusses the highlights of legislation on video recording in health care. In addition, applications of video recording in clinical practice are discussed as well as the practical interpretation of legislation for these applications. Finally, court cases are discussed in which video data from a clinical setting are proposed to serve as evidence. The focus is on Dutch law, but similar principles are found in the jurisprudence of all Western countries. Additional attention is paid to U.S. law because of all Western countries, the U.S. law system deviates most from the Dutch system.

\section{Methods}

Legislation and literature regarding video recording in health care were studied.
Legislation on video recording in health care

National and international law was studied to discover the legal framework of video recording in health care. National legislation was studied on the Web site of the Dutch government [7]. International law was studied in the Westlaw database, the Web site of the U.S. Department of Health and Human Services [8], and in the report of Legrand et al. [9] on video registration of endoscopic surgical interventions.

Applications in clinical practice and practical interpretation of legislation

A literature study was performed to identify applications, regulations, and concerns of video recording in health care. The database of Web of Knowledge was searched by using search terms that included "video", "purpose/benefit/value", "safety", "health care/care/hospital/operating room", and "legal/jurisprudence/law".

Court cases with health care videos as evidence

Jurisprudence was studied to find examples of court cases in which video recordings from clinical practice have been used or proposed for use as evidence. This was studied on the Web site of Dutch jurisprudence [10] and the Web site of the Dutch disciplinary tribunal of health care [11].

\section{Results}

Legislation on video recording in health care

The relevant laws for video recording in health care in Western countries are based on three principles: privacy regarding personal data, the patient record, and professional secrecy. Regulations differ across countries regarding the number of laws that apply and the strictness of the regulations. Safety and quality of health care in the Netherlands are established in a number of laws including the Individual Health Care Professions Act (in Dutch: Wet op de beroepen in de individuele gezondheidszorg [BIG]) and the Agreement on Medical Treatment Act (in Dutch: Wet op de geneeskundige behandelinsovereenkomst [WGBO]).

In addition to these laws, privacy of personal data is protected by the Personal Data Protection Act (in Dutch: Wet bescherming persoonsgegevens [WBP]). Moreover, the Royal Dutch Society for advancement of Medicine (in Dutch: Koninklijke Nederlandsche Maatschappij tot bevordering der Geneeskunst [KNMG]) has published guidelines for handling medical data [12]. This document 
includes guidelines regarding seizure of video data, video data for educational purposes, and security videos.

In the United States, the Health Insurance Portability and Accountability Act (HIPAA) [8] is set up specifically to protect the privacy of patients' health information. The HIPAA legislation is supplemented by state law and institutional regulations. An overview of the relevant laws and organizations is given in Box 1.

\section{Privacy}

Internationally recognized guidelines on the protection of privacy and transborder flows of personal data are set up by the Organization for Economic Cooperation and Development (OECD) [13]. These guidelines include eight principles (Box 2). Based on these guidelines, the European Union set up regulations in EU Directive 95/46 that aim at protecting privacy. Consequently, the law on privacy in EU countries contains the same principles.

The Dutch implementation of this EU Directive is the WBP. The WBP confines the processing of personal data, defined as any information about an identified or identifiable natural person including video data. The HIPAA legislation contains the same topics as the internationally recognized principles of privacy, but the regulations are less strict than the Dutch regulations.

\section{Patient record}

Care providers are obliged to keep a medical record of each patient. All information relevant to providing good care should be included, but the care providers decide on the exact content of the patient record. Good care in this respect is defined as care that is in accordance with the relevant professional standard. National and regional regulations may describe the content of the patient record in more detail, but it usually remains unclear whether video recordings of health care should be included or not. Regulations on the ownership of the patient record and its content are lacking as well. However, the right of patients to access their patient record is established in the legislation of all Western countries.

In the Netherlands, the WGBO prescribes that health care professionals are obliged to keep a patient record. Whenever video data are included in a patient record, these should be accessible to the patient and stored for at least 15 years. When video data are not included in a patient record, the WBP applies. The WBP entitles patients and professionals involved to request information on whether their video data are being processed or not. In the United States, HIPAA protects any personal information about a patient whether it is included in a patient record or not. The distinction between information included in a patient record and information excluded from a patient record is therefore not as pronounced as in the Netherlands.

\section{Professional secrecy}

Professional secrecy consists of two parts: confidentiality and the right of nondisclosure. Confidentiality is based worldwide on the Hippocratic Oath that states: "I will respect the privacy of my patients." To enable this juridical, health care professionals have the right of nondisclosure. Differences are seen across countries regarding the number and type of situations in which health care professionals are allowed or even obliged to lift confidentiality. These differences are raised by the trade-off between the right to privacy and public interest. Public interest includes reporting certain infectious diseases or child abuse, but it also includes disclosure for the purpose of averting, preventing, detecting, and convicting of crimes.

In the Netherlands, professional secrecy is established in WGBO article 457 and in BIG article 88 and applies to any information that a medical professional gathers about a specific patient in any way during the practice of medicine. Professional secrecy can be lifted only after authorization of the patient, when there is a legal ground to do so, or when the professional has a conflict of duties. The U.S. legislation on disclosure of personal health information is more limited than the Dutch legislation. In addition to the previously mentioned situations, HIPAA allows health care professionals to disclose protected health information for several purposes in law enforcement [8].

\section{Applications of video recording in clinical practice}

Several types of video are being recorded throughout clinical practice, varying from endoscopic video images to overviews of operating rooms and surveillance videos. In

Box 1 Abbreviations for Dutch names (if applicable) and English names of relevant laws and organizations

\begin{tabular}{lll}
\hline BIG & Wet op Beroepen in de Individuele Gezondheidszorg & Individual health care professions act \\
WGBO & Wet op de Geneeskundige Behandelingsovereenkomst & Agreement on medical treatment act \\
WBP & Wet Bescherming Persoonsgegevens & Personal data protection act \\
KNMG & Koninklijke Nederlandse Maatschappij tot bevordering der Geneeskunst & Royal Dutch society for advancement of medicine \\
HIPAA & - & Health insurance portability and accountability act \\
OECD & - & Organization for economic cooperation development \\
\hline
\end{tabular}


Box 2 Eight principles regarding the privacy of transborder personal data flows set up by the organization for economic cooperation and development (OECD)

1. Collection limitation principle

There should be limits to the collection of personal data, and any such data should be obtained by lawful and fair means, and where appropriate, with the knowledge or consent of the data subject

2. Data quality principle

Personal data should be relevant to the purposes for which they are to be used, and to the extent necessary for those purposes, should be accurate, complete, and kept up-to-date

3. Purpose specification principle

The purposes for which personal data are collected should be specified not later than at the time of data collection and the subsequent use limited to the fulfillment of those purposes or such others as are not incompatible with those purposes and as are specified on each occasion of change of purpose

4. Use limitation principle

Personal data should not be disclosed, made available, or otherwise used for purposes other than those specified except with the consent of the data subject or by the authority of law

5. Security safeguards principle

Personal data should be protected by reasonable security safeguards against such risks as loss or unauthorized access, destruction, use, modification or disclosure of data

6. Openness principle

There should be a general policy of openness about developments, practices, and policies with respect to personal data. Means should be readily available for establishing the existence and nature of personal data, and the main purposes of their use, as well as the identity and usual residence of the data controller

7. Individual participation principle

An individual should have the right to obtain confirmation from a data controller whether or not the data controller has data relating to him; to have communicated to him, data relating to him within a reasonable time; and to challenge data relating to him, and if the challenge is successful, to have the data erased, rectified, completed, or amended

8. Accountability principle

A data controller should be accountable for complying with measures which give effect to the principles stated above

addition to endoscopic video recordings, the use of conventional video recording of patients and professionals is increasing as well. Xiao et al. [1] give a comprehensive overview of different applications for video recording in a health care setting, but there are more applications. The regulations that apply depend on the nature and purposes of the video recording but often are not clear to the people involved. The following sections describe clinical applications of video recording.

\section{Endoscopy}

In MIS, an endoscope is used to view the operating field inside the patient during a treatment without opening up the patient. Video recording is essential during these types of interventions, but the video data are not necessarily stored afterward.

\section{Surveillance}

Hospitals regularly have to deal with violence against people and equipment. Especially in the emergency rooms, this is a growing problem [14-16]. Surveillance cameras are increasingly used to protect people and property.

\section{Education}

Video data also are used in the teaching and training of students and professionals. Video data are used before, during, and after an intervention or process. In advance, data can serve as a guide or as a best practice to teach students or to prepare professionals for a difficult procedure. During treatments, videos are used to teach students or to provide information to an advisor at a remote location. An example of a remote real-time educational video system is described by Hahm et al. [17]. After a treatment, video data can be used for evaluation, for instance when attending professionals want to evaluate a new procedure or to improve their skills.

\section{Organization}

Video images are used in a health care facility to improve or streamline the organization as well. Hu et al. [18], for example, describes the design of a visualization platform to provide more information for coordination. This platform displays video data from within the operating room, including patient vital signs, which improve the awareness of availability of space, equipment, and personnel. Videos 
also can be used for command and control, retrospectively. The video recordings of an entire surgical or medical procedure can be incorporated with the electronic patient record (e.g., facilitated by a voice-activated operative note dictation system). This allows in-depth review after the procedure is completed, for instance, when a complication occurs.

\section{Research}

Video data can play a role in research that aims at improving the quality, safety, or efficiency of health care. Video-based research typically contributes to the identification of necessary improvements and to the evaluation of new equipment, techniques, or processes. Topics in videobased research include team performance, medication safety, functioning of technical equipment, evaluation of technical skills, workflow or treatment approaches, and many more.

Numerous studies on improving quality of care are found in the literature. Mackenzie et al. [19] changed the operating procedure to reduce the number of undetected incorrect tracheal intubations. Blom et al. [20] classified and scored communication for the purpose of an improved training process. Aggarwal et al. [21] used video to track motion for objective, instant, and automated assessment of laparoscopic skills in the operating room. Weinger et al. [22] designed a digital video data collection system for use in patient safety during anesthesia. Verdaasdonk et al. [23] performed an observational study to investigate the incidence of technical equipment problems during laparoscopic cholecystectomies.

\section{Patients' private use}

Currently, video recordings are regularly made for private use by patients or their relatives. The general goal of these recordings is to improve the way patients and their relatives experience a treatment. An example of this is seen in the obstetric department of hospitals, where parents regularly wish to record the birth of their baby. Another example of video recording for patients and their relatives is a webcam service for parents and their hospitalized children.

Interpretation of legislation for the applications

Endoscopy differs from the other applications in clinical practice because video recording is an essential part of the intervention. It may be argued that they are anonymous because endoscopic videos show only the inside of the patient. However, the patient and the professional may be indirectly identifiable, for example, by referring time stamps of the videos to operation schedules. As such, patients are identifiable on endoscopic images, and privacy principles apply.

Authorization for making endoscopic videos is included in the authorization for the complete treatment because endoscopic videos are closely related to the actual treatment. Because of this close relation, it could be argued that part of the endoscopic video data should be included in the patient record. The included images then must be treated as any other part of the record. Apart from certain exceptions, third parties are not allowed to access endoscopic videos because endoscopic video data are included in professional secrecy.

For all applications other than endoscopy, legislation applies differently. Unless recorded people are rendered completely anonymous in video data, privacy principles apply to all previously discussed types of video data. In the Netherlands, this means that data can be collected only for specific, clearly predefined, justifiable purposes and that personal details cannot be processed for aims incompatible with the original aim. Furthermore, any person involved, including patients and professionals, has to be informed in advance about the nature and purpose of the video recording. This person also has to authorize being recorded.

Because video data for the previously described purposes are not directly linked to a treatment, such data do not have to be included in a patient record. An exception to this is video data for research that comprises a medical treatment. In the Netherlands, data not included in a patient's record are not necessarily accessible to the patient. However, in the United States, any type of personal health information should be accessible to the patient regardless whether it is a part of the patient's record or not. In most cases, the privacy of patients may be sufficiently protected by professional secrecy, although it is not clear to what extent the right of nondisclosure applies due to the more general character of the video data. The privacy of professionals is protected by legislation on the processing of personal data. It is not clear, however, to what extent their privacy is protected when information is included in a patient's record. The patient is allowed to obtain any information from his or her record, but it is not addressed whether the patient should get authorization of the concerned professionals or not when this information is shown to third parties.

In court

Although it is not the original purpose, information about patients, including video data, may be used as evidence in a court hearing. In Dutch jurisprudence, cases are found in which written or visual material is allowed in court proceedings. To date, this has happened only when the medical professional himself is suspected of a severe penal 
offence [24]. This is illustrated by two examples. In the first example, a woman got pregnant after being sterilized [25]. The court requested an expert to assess the performance of the physician who performed the sterilization. For that purpose, the court allowed the operation report of the sterilization and the video made during the resterilization.

In another case [26], a mother was suspected of involvement in Pediatric Condition Falsification (PCF or Munchhausen by proxy) when her son experienced multiple apparent life-threatening events that could not be explained on medical grounds. To verify the diagnosis of the son, recordings were obtained with a hidden camera, which confirmed the suspicion of the physicians. The court seized the video tapes when the child died, but the hospital objected to this. The court of appeal decided that in this case, patient confidentiality was more important than discovering the truth, especially because it could not be ruled out that the necessary information also could be obtained without breaking professional confidentiality. Therefore, the video images of the patient were not allowed, although the parents authorized the disclosure.

Professional secrecy and the right of nondisclosure may not apply to information that is not about a specific patient. In Dutch practice, these data seem to be less protected from seizure than information to which professional secrecy applies. An example of such data is information from "Safely Reporting Incidents" (Veilig Incident Melden). In a number of cases, the court has decided that discovery of the truth is prevailing over the confidentiality of reporting incidents in patient care [27-29]. This indicates that when the information does not relate to a specific patient, it is more likely that data, including video data, will be allowed in a court hearing. In the end, it is for the judge to decide which evidence may be put forward in a case.

\section{Discussion}

We have found that throughout Western legislation, laws on privacy regarding personal data, laws on the patient record, and laws on professional secrecy apply analogically to video recording in health care. In the Netherlands, the WBP aims at protecting the privacy of personal data, and the WGBO contains legislation about the patient record and professional secrecy. Legislation on professional secrecy is complemented in BIG. In America, legislation on the three topics is established in HIPAA, which is complemented by state law and institutional regulations.

Laws on privacy of personal data require that patients and professionals be informed about the purpose and the nature of video recording and that authorization be obtained whenever possible. Laws on the patient record state that relevant information must be included in the patient record. This information can include video data in certain situations, but guidelines on the exact content of a patient record are lacking. Laws on professional secrecy require that no patient information be disclosed unless legal ground exists for doing so, for example, in cases of child abuse or when the court allows the disclosure.

Numerous applications of video recording are found in clinical practice including endoscopy, surveillance, education, organization, research, and a patient's private use. In endoscopy, video recording is an essential part of the treatment. Authorization for video recording is therefore included in authorization of the complete treatment. It could be advisable to include endoscopic video data in the patient record. Whether this is the case or not, privacy of the patient is protected by professional secrecy. In all the other applications, video data usually do not have to be included in the patient record. Privacy is protected by legislation regarding personal data. The privacy of patients is further protected by professional secrecy.

Although current legislation applies analogically to video data in health care, practical interpretation is not straightforward. Therefore, the current legislation needs a practical translation for use in a clinical setting. It is advisable to

1. Make explicit descriptions of what legislation applies and translate these into practical regulations that specifically apply to different types of video recording in health care. These regulations should answer questions such as "What can be recorded for what purposes?" "What is the legal position of video data in health care?" "What are the rights of professionals, patients, health care institutions, government, and police?" "How should data be processed, protected, and stored?" "Which (endoscopic) video data should be included in a patient record?" "Is video analysis as a tool for assessment of proficiency under the present circumstances justified?" and "Do the regulations also apply to live transmissions?"

2. Take into account the nature of video data. On the one hand, video images reveal more information than more conventional data such as static images or notes in a patient record. Therefore, video images are more invading to privacy than is accounted for in current law. On the other hand, video data show only a part of the relevant context. Additional information may be needed for proper interpretation of the video data. Besides this, interpretation of video data is dependent on the observer. De Reuver et al. [30] showed that agreement among health care professionals with regard to defining proper care can be poor, but Emous et al. [31] showed that interobserver reliability is improved 
when video data are used instead of photos. Finally, video data do not necessarily contain information that is supplementary to other available data, in which case it has no added value.

3. Ensure that the privacy of professionals is respected to the same extent as the privacy of patients. Current regulations that apply to video recording in health care aim mainly at protecting the privacy of patients while paying limited attention to the privacy of professionals.

The current report aims to provide insight into the legal implementation framework of video use in health care in Western countries. The focus is on the privacy and the juridical position of the patient and the professional. Dutch and American legislation are taken as illustrating examples. However, legislation in other European countries contains principles similar to those in the Dutch legislation. Implementation of practical regulations needs to be investigated to ensure that the regulations are practicable.

Technological development also can contribute to protection of privacy. For instance, data can be deleted automatically after use, even when these data might be useful in the future. Another measure for protecting privacy is to automatically make video data completely anonymous. The development of a system that provides feedback about the condition of patients or equipment to professionals by real-time analysis of video images can contribute to safer health care while ensuring the privacy of patients and professionals as well. Before video registration can be used as a tool for quality evaluation, optimal performance must be clearly defined. Besides that, registration systems must be able to register all essential details while respecting people's privacy.

We conclude that video recording can greatly contribute to the improvement of patient safety but that practical regulations on its use in health care are lacking. In particular, clear guidelines on the inclusion of video data in a patient's record are missing. For the use of video in educational, organizational, and research settings, making the video data anonymous automatically can contribute to protection of privacy for all the people involved. This may help to reduce the reluctance among health care professionals to implement structural recordings. It is therefore of great importance to stimulate socially and ethically sensible technical innovation in health care.

Acknowledgments This research was supported by the Netherlands Organization for Scientific Research (Grant 313-99-003).

Disclosures Kirsten R. Henken, Frank Willem Jansen, Jan Klein, Laurents P. S. Stassen, Jenny Dankelman, and John J. van den Dobbelsteen have no conflicts of interest or financial ties to disclose.

Open Access This article is distributed under the terms of the Creative Commons Attribution License which permits any use, distribution, and reproduction in any medium, provided the original author(s) and the source are credited.

\section{References}

1. Xiao Y, Schimpff S, Mackenzie C, Merrell R, Entin E, Voigt R, Jarrell B (2007) Video technology to advance safety in the operating room and perioperative environment. Surg Innov 14:52-61

2. Ellis DG, Lerner EB, Jehle DV, Romano K, Siffring C (1999) A multistate survey of videotaping practices for major trauma resuscitations. J Emerg Med 17:597-604

3. Guerlain S, Turrentine B, Adams R, Calland JF (2004) Using video data for the analysis and training of medical personnel. Cognit Technol Work 6:131-138

4. Guerlain S, Adams RB, Turrentine FB, Shin T, Guo H, Collins SR, Calland JF (2005) Assessing team performance in the operating room: development and use of a "black-box" recorder and other tools for the intraoperative environment. J Am Colloid Surg 200:29-37

5. IGZ (2007) Risks of minimally invasive surgery underestimated: a report of the Dutch Health Care Inspectorate. Dutch Healthcare Inspectorate, Den Haag

6. Blaauw CB, Hubben JH (2010) De videocamera in de operatiekamer vanuit gezondheidsrechtelijk perspectief. ISBN-13: 978-90-816565-1-1. University Medical Center Groningen, Groningen

7. Web site of Dutch government (2011) Retrieved at http://wetten. overheid.nl/zoeken/. Accessed 23 April 2012

8. Web site of U.S. Department of Health \& Human Services (2002) Retrieved at http://www.hhs.gov/ocr/privacy/. Accessed 23 April 2002

9. Legrand M, Coudron V, Tailleu I, Rooryck N, Dupont K, Boudrez P, Senn A, Vinck I, Peeters G, Kohn L (2008) Videoregistratie van endoscopische chirurgische interventies: rapid assessment. Health Technology Assessment (HTA). Federaal Kenniscentrum voor de Gezondheidszorg (KCE), Brussels

10. Web site of Dutch jurisprudence. Retrieved at http://jure.nl/. Accessed 23 April 2012

11. Web site of Dutch disciplinary tribunal of health care. Retrieved at http://www.tuchtcollege-gezondheidszorg.nl/uitspraken/. Accessed 23 April 2012

12. Koninklijke Nederlandsche Maatschappij tot bevordering der Geneeskunst (KNMG) (2010) Guidelines for the use of medical data. Royal Dutch Medical Association, Utrecht Retrieved at www.knmg.nl/publicatie/medischegegevens. Accessed 23 April 2012

13. Organization for Economic Cooperation and Development (OECD) (1980) Guidelines on the protection of privacy and transborder flows of personal data. Retrieved at http://www.oecd. org. Accessed 23 April 2012

14. Behnam M, Tillotson RD, Davis SM, Hobbs GR (2011) Violence in the emergency department: a national survey of emergency medicine residents and attending physicians. J Emerg Med 40:565-579

15. Lyneham J (2001) Violence in New South Wales emergency departments. Aust J Adv Nurs 18:8-20

16. Jenkins MG, Rocke LG, McNicholl BP, Hughes DM (1998) Violence and verbal abuse against staff in accident and emergency departments: a survey of consultants in the UK and the Republic of Ireland. J Accid Emerg Med 15:262

17. Hahm JS, Lee HL, Kim SI, Shimizh S, Choi HS, Ko Y, Lee KG, Kim TE, Yun JW, Park YJ (2007) A remote educational system 
in medicine using digital video. Hepatogastroenterology 54:373-376

18. Hu PF, Xiao Y, Ho D, Mackenzie CF, Hu H, Voigt R, Martz D (2006) Advanced visualization platform for surgical operating room coordination: distributed video board system. Surg Innov 13:129-135

19. Mackenzie CF, Xiao Y, Hu FM, Seagull FJ, Fitzgerald M (2007) Video as a tool for improving tracheal intubation tasks for emergency medical and trauma care. Ann Emerg Med 50:436-442

20. Blom EM, Verdaasdonk EGG, Stassen LPS, Stassen HG, Wieringa PA, Dankelman J (2007) Analysis of verbal communication during teaching in the operating room and the potentials for surgical training. Surg Endosc 21:1560-1566

21. Aggarwal R, Grantcharov T, Moorthy K, Milland T, Papasavas P, Dosis A, Bello F, Darzi A (2007) An evaluation of the feasibility, validity, and reliability of laparoscopic skills assessment in the operating room. Ann Surg 245:992-999

22. Weinger MB, Gonzales DC, Slagle J, Syeed M (2004) Video capture of clinical care to enhance patient safety. Qual Saf Health Care 13:136-144
23. Verdaasdonk EGG, Stassen LPS, Van Der Elst M, Karsten TM, Dankelman J (2007) Problems with technical equipment during laparoscopic surgery. Surg Endosc 21:275-279

24. Bannier FAW, Duijst WLJM, Fanoy NAMEC, Meijers APH, Tempelaar JM (2008) Beroepsgeheim en verschoningsrecht: handboek voor de advocaat, medisch hulpverlener, notaris en geestelijke. Sdu Uitgevers, Den Haag

25. (2007) LJN BA1093. Supreme Court of the Netherlands

26. (2009) LJN BG5979. Supreme Court of the Netherlands

27. (2002) LJN AE8470. Court of Utrecht district

28. (2007) LJN BC1286. Court of Zwolle district

29. (2009) LJN BH9159. Court of Arnhem district

30. De Reuver PR, Dijkgraaf MGW, Gevers SKM, Gouma DJ (2008) Poor agreement among expert witnesses in bile duct injury malpractice litigation: an expert panel survey. Ann Surg 248:815-820

31. Emous M, Westerterp M, Wind J, Eerenberg JP, Van Geloven AAW (2010) Registering the critical view of safety: photo or video? Surg Endosc 24:2527-2530 